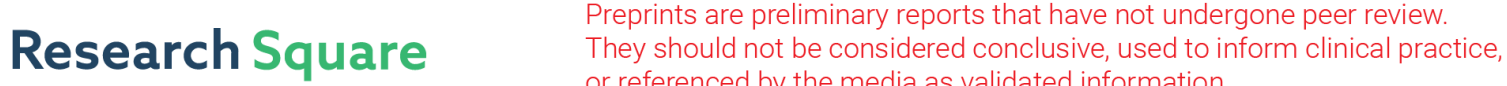 or referenced by the media as validated information. \\ Multi-timescale control of Southern Ocean diapycnal mixing over Atlantic tracer budgets
}

Elizabeth Ellison ( $\square$ ece1818@ic.ac.uk)

Imperial College London https://orcid.org/0000-0002-4087-8251

Ali Mashayekh

Imperial College London

Laura Cimolo

University of California San Diego Scripps Institution of Oceanography

\section{Research Article}

Keywords: Southern Ocean, Turbulent Mixing, Carbon cycle, Tracer budgets

Posted Date: December 2nd, 2021

DOI: https://doi.org/10.21203/rs.3.rs-1127905/v1

License: (c) (i) This work is licensed under a Creative Commons Attribution 4.0 International License.

Read Full License 


\title{
Multi-timescale control of Southern Ocean diapycnal mixing over Atlantic tracer budgets
}

\author{
Elizabeth Ellison ${ }^{1 *}$, Ali Mashayek ${ }^{1}$ and Laura Cimoli ${ }^{2}$ \\ $1^{*}$ Imperial College, London, UK. \\ ${ }^{2}$ Scripps Institution of Oceanography, USCD, USA.
}

\begin{abstract}
*Corresponding author(s). E-mail(s): e.ellison18@imperial.ac.uk; Contributing authors: mashayek@ic.ac.uk; lcimoli@ucsd.edu;
\end{abstract}

\begin{abstract}
Oceanic cross-density (diapycnal) mixing helps sustain the ocean density stratification and its Meridional Overturning Circulation (MOC) and is key to global tracer distributions. The Southern Ocean (SO) is a key region where different overturning cells connect, allowing nutrient and carbon rich Indian and Pacific deep waters, and oxygen rich Atlantic deep waters to resurface. The SO is also rife with localized intense diapycnal mixing due to breaking of internal waves induced by the interaction of energetic eddies and currents with rough topography. SO diapycnal mixing is believed to be of secondary importance for the MOC. Here we show that changes to SO mixing can cause significant alterations to Atlantic biogeochemical tracer distributions over short and long timescales in an idealized model of the MOC. While such alterations are dominated by the direct impact of changes in diapycnal mixing on tracer fluxes on annual to decadal timescales, on centennial timescales they are dominated by the mixing-induced variations in the advective transport of the tracers by the Atlantic MOC. This work suggests that an accurate representation of spatio-temporally variable local and non-local mixing processes in the SO is essential for climate models' ability to i) simulate the biogeochemical cycles and air sea carbon fluxes on decadal timescales, ii) represent the indirect impact of mixinginduced changes to MOC on biogeochemical cycles on longer timescales.

Keywords: Southern Ocean, Turbulent Mixing, Carbon cycle, Tracer budgets
\end{abstract}


Control of Southern Ocean mixing on tracer budgets

\section{Introduction}

In the ocean interior and away from boundaries, internal waves are mainly radiated by winds at the surface and by tidal and deep geostrophic flows interacting with rough bottom topography [1]. Breaking of internal waves induces turbulent mixing across density surfaces (i.e. diapycnally), which modifies water mass properties, maintains ocean stratification, and contributes to sustaining the deep branches of the global Meridional Overturning Circulation (MOC). Mixing is also key to redistribution of heat, carbon, biological nutrients, and other tracers globally and in depth [2-5]. Ocean circulation models do not resolve the processes responsible for diapycnal mixing and parameterize diapycnal mixing in terms of a turbulent effective diffusivity, $\mathcal{K}[6-9]$.

\subsection{Southern Ocean dynamics}

Unbounded by continents, the SO is a crucial link between waters formed in different ocean basins, and inter basin exchanges of heat, carbon, nutrients and other tracers [10]. The lack of boundaries generates unique regional dynamics by allowing for the formation of the Antarctic Circumpolar Current system (ACC), an uninterrupted deep-reaching eastward flow driven by strong westerly winds. Within the ACC and in the upper ocean, the wind-driven Ekman transport is balanced by the resurfacing of deep waters. The Ekman transport is northward within the latitude band of the westerly winds, but southward towards Antarctica where easterly winds blow. In the deep SO, the zonal pressure gradient sustained by deep topography allows for northward transport of the abyssal waters that form and sink around Antarctica [11-13]. While the Ekman transport primarily induces isopycnal (i.e. along density surfaces) water transports, in the $\mathrm{SO}$ interior diapycnal mixing allows for further vertical mixing of waters and tracers [14-16]; see Fig. 1.

Within the SO, deep waters are upwelled adiabatically (i.e. along isopycnals) and are modified by surface buoyancy forcing upon turbulent entrainment into the mixed layer $[17,18]$. Indian and and Pacific deep waters predominantly upwell into a region of positive buoyancy forcing and form the northwardflowing Antarctic Intermediate Water (AAIW) and South Antarctic Mode Water (SAMW) $[18,19]$. These waters eventually return to the SO as North Atlantic Deep Waters (NADW), completing the upper MOC cell (Red arrows in Fig. 1). Alternatively, waters can upwell into a region of negative buoyancy forcing in the SO, as happens for up to $75 \%$ of the NADW, forming the denser Antarctic Bottom Waters (AABW) [10, 18-22]. These abyssal waters sink and move northward along topographic ridges and canyons, and are then converted to deep waters through diapycnal mixing above the rough seafloor $[12,23]$ (Orange arrows in Fig. 1), forming the lower MOC cell (Blue arrows).

The SO is known to have high rates of diapycnal mixing from direct observational estimates, inverse bulk budgets, and numerical models [14, 16, 24-27]. This mixing is generated by strong ACC bottom currents interacting with 
rough topography, causing internal wave breaking over abyssal ridges, mountains and rises [24, 28, 29] (Orange arrows in Fig. 1). Studies have reported strong variations in diapycnal mixing rates for different regions of the $\mathrm{SO}$, ranging from $10^{-5} \mathrm{~m}^{2} \mathrm{~s}^{-1}$ to $10^{-3} \mathrm{~m}^{2} \mathrm{~s}^{-1}$.

\subsection{Southern Ocean biogeochemistry}

$65 \%$ of interior ocean waters make first contact with the atmosphere in the SO [30, 31], with Pacific and Indian deep waters bringing waters rich in dissolved inorganic carbon (DIC) and nutrients to the surface [21]. Thus, the SO connects the vast reservoir of nutrients and carbon below the mixed layer with the surface [19] $\left(\mathrm{DIC}^{+}\right.$and $\mathrm{N}^{+}$grey waters in Fig. 1). Vigorous vertical diapycnal mixing also enhances the supply of nutrients from the deep ocean to the surface [31]. Globally, the supply of surface nutrients is dominated by their upwelling in the SO [31, 32]. Patterns of SO circulation are therefore key to controlling the global biogeochemical cycles, the exchange of carbon dioxide $\left(\mathrm{CO}_{2}\right)$ between the atmosphere and the deep ocean, and the response of the ocean and atmosphere to climate change [33,34]. The upwelling branch of the MOC, in particular, is key to controlling the global climate from both dynamical and biochemical perspectives [19].

The global distribution of conservative and non conservative tracers have been shown to be sensitive to ocean circulation and ventilation [35-37]. Enhanced mixing increases the deep ocean ventilation via the $\mathrm{SO}$ and reduces ocean carbon storage through the biological and solubility carbon pumps $[21,38]$. Enhancement in SO diapycnal mixing is known to be able to alter tracer distributions through increased ventilation of intermediate waters [36]. Such changes are believed to be indirect since they are due to the interior diapycnal mixing altering the MOC over centennial to millennial timescales.

Theoretical studies have highlighted that diapycnal mixing rates in the deep SO are not to be of leading-order importance for regulating the global MOC, secondary to the role of winds, eddies, and surface buoyancy forcing. However, mixing in the ocean basins to the north of the SO play a primary role in regulating the ocean circulation, and close the MOC by upwelling the abyssal waters that form and sink at high latitudes [8, 8, 12, 39-41]. Limited work has been carried out to assess the sensitivity of biogeochemical tracer distributions to SO diapycnal mixing rates.

In this work, we examine the role of diapycnal mixing in the $\mathrm{SO}$ on Atlantic tracer budgets over varying timescales, and whether these changes are due to altered tracer diffusion or advection. We show that diapycnal mixing in the SO is crucial in setting the distribution of tracers on a range of timescales through two mechanisms. On long time scales, circulation and tracer advection changes dominate, especially when looking at changes to distribution on a global scale, whereas over short time scales, changes to tracer diffusion dominate, especially for changes within the SO only. 


\section{Model Description}

This work uses the zonally averaged model of the Atlantic MOC (AMOC) by [41] (hereafter NV12), extended in [42] to include a simple biochemical model based on that introduced in [43]. The model, and similar ones, have been used extensively over the past decade to study various aspects of the role of the MOC in the climate system from both dynamical and biochemical aspects (e.g. $[42,44-47]$. Thus, we simply provide a brief phenomenological description of the model here and refer the reader to the original works for more details.

\subsection{The physical model}

In the NV12 model, the Atlantic Ocean is split into three key areas: a SO circumpolar channel, a North Atlantic deep water formation zone, and the ocean basin that connects the two (consistent with the schematic in Fig. 1). While NV12 employed a constant $\mathcal{K}$ value throughout the water column in all three zones, here we consider vertically-variable mixing and distinguish between the mixing in the basin from that in the SO. It is the impact of variations in the latter that we explore herein to study the sensitivity of tracer distributions to $\mathrm{SO}$ diapycnal mixing.

\subsection{The Biochemical model}

The simple biogeochemical component that was added to NV12 in [42] allows for representation of the coupled evolution of nutrients $(\mathrm{N})$ and carbon $(\mathrm{C})$, where $\mathrm{N}$ represents the ultimate limiting nutrient phosphate. Organic material is parameterized to sink downward, measured in units of phosphate, with the biological export timescale set to 360 days. A well-mixed atmospheric box is coupled to the ocean carbon cycle such that the partitioning of $C$ between the atmosphere and the ocean is explicitly calculated in the model. The model conserves the total amount of $C$ in the atmosphere and the ocean; if $C$ is gained in the ocean, it must be lost in the atmosphere.

The biogeochemical tracers $(\mathrm{C}, \mathrm{N})$ are transported by advection and diffusion and have sources and sinks via biological activity $\left(\mathrm{F}_{p}\right)$ of uptake and remineralization. The concentration of $C$ is able to change via surface fluxes driven by $\mathrm{pCO}_{2}$ differences to account for air-sea gas transfer. More explicitly, the equations for $C$ and $N$ are

$$
\begin{array}{r}
\delta_{t} N+J(\psi, N)=\delta_{z}\left(\mathcal{K} \delta_{z} N\right)+\delta_{z} F_{p}, \\
\delta_{t} C+J(\psi, C)=\delta_{z}\left(\mathcal{K} \delta_{z} C\right)+R \delta_{z} F_{p}+C_{\text {flux }} \|_{z=0}, \\
C_{\text {flux }}=-(k w \times k H) \times\left(p C O_{2} a-p C O_{2} o\right) \times(1-\text { icecover }),
\end{array}
$$

where $\psi$ is the meridional overturning streamfunction representing the AMOC (Fig.1, Fig.3a,b), $k w$ is the air sea $\mathrm{CO}_{2}$ exchange constant and $k \mathrm{H}$ is the fugacity of $\mathrm{CO}_{2}$. The second term on the LHS represents advection of $\mathrm{N}$ and $C$ by the MOC, the first term on the RHS represents turbulence diapycnal 
mixing, and the final term represents biological activity [43]. Biological activity in surface waters removes both nutrients and carbon at the ratio set by $R$, with carbon and nutrients both released by respiration as organic matter sinks.

\subsection{Experiment Design}

Our goal is to explore the sensitivity of the MOC and tracer budgets to SO mixing. Figure 2a shows the diapycnal mixing, $\mathcal{K}$, in the deep Atlantic region based on the tidal mixing estimates of [48] and the lee wave mixing estimates of [29] combined. While lee-wave-induced mixing is dominant in the SO due to strong eddy/current interaction with topography, tidal mixing is dominant in the basin to the north due to tidal flow interaction with the midAtlantic ridge. Panel b shows the global zonally-averaged diapycnal mixing in the SO from a combination of internal tides, lee waves and surface-enhanced, wind-induced mixing based on the observationally-constrained Southern Ocean Estate Estimate [49]

In all experiments (soon to be discussed) the mixing in the ocean basin will be fixed to the Atlantic basin averaged $\mathcal{K}_{B}$ shown by the blue curve in figure 2c. All surface forcings are also kept constant in all experiments, and are as prescribed in [29]. In the SO, we consider three paradigms: the Low mixing scenario of $\mathcal{K}_{\mathcal{L}}=10^{-5} \mathrm{~m}^{2} / \mathrm{s}$, the High mixing scenario of $\mathcal{K}_{\mathcal{H}}=10^{-4} \mathrm{~m}^{2} / \mathrm{s}$, and the Realistic mixing scenario motivated by figure $2 \mathrm{~b}$, referred to as $\mathcal{K}_{R}$. It should be noted that $10^{-5}$ and $10^{-4} \mathrm{~m}^{2} / \mathrm{s}$ are canonical values in physical oceanography, respectively representing the background mixing in the ocean and the mixing required for closure of the $\operatorname{MOC}[2,46,50,51]$.

Since $\mathcal{K}_{B}$ will be fixed in all experiments, hereafter we will use $\mathcal{K}_{R}, \mathcal{K}_{L}$, and $\mathcal{K}_{H}$ to name the experiments. While in some cases the same SO diffusivity will be applied to density, $N$, and $C$, in others we will apply a mixing profile to $N$ and $C$ that is different from that applied to density. This will be done to distinguish between the direct impact of mixing on tracers from the indirect effect on tracers because of the changes to the MOC induced by mixing of density. Thus, in naming of the experiments we will use superscripts ' $t$ ' and ' $\rho$ ' to refer to tracer and density mixing. For example, an experiment named $\left[\mathcal{K}_{H}^{t}, \mathcal{K}_{L}^{\rho}\right]$ refers to one in which high SO mixing acts on tracers while low SO mixing acts on density whereas $\mathcal{K}_{L}$ simply refers to an experiment in which low SO mixing is applied to both tracers and density.

The $\mathcal{K}_{L}$ experiment, hereafter referred to as the 'control', is run until an equilibrated overturning circulation is achieved (4000 yrs) and then extended until the ocean biogeochemistry reaches an equilibrated state as well (another $4000 \mathrm{yrs}) . C$ and $N$ are initialized with uniform concentrations $\left(2.2 \mathrm{e}^{-3} \mathrm{~mol} N\right.$ $m^{-3}$ and $2.2 \mathrm{~mol} \mathrm{C}^{m-3}$ respectively [42]). The atmospheric carbon concentration is set to 278 part per million (ppm), representative of the pre-industrial level [43]. Starting from this equilibrated $\mathcal{K}_{L}$ solution, we run a host of configurations varying the $\mathrm{SO}$ density and tracer diffusivities. Each run is $4000 \mathrm{yr}$ long so that a new equilibrium is achieved. In this work we examine changes to both transient model solutions and the equilibrated changes for each experiment. 


\subsection{Model Verification}

Figure 3 compares the model solution for the control case to the circulation inferred from a climatologically-constrained ocean state estimate (ECCO [52]). In the control run $\left(\mathcal{K}_{L}\right)$, the upper cell extends to $\sim 2000 \mathrm{~m}$ deep with a maximum strength of $17 \mathrm{~Sv}$ while the lower cell transport is about $4 \mathrm{~Sv}$ (Fig.3b), both well within the range of inverse models [10, 53] and ocean state estimates $[9,52]$. Panel $c$ compares the model stratification in the Atlantic basin (for experiments $\mathcal{K}_{L}, \mathcal{K}_{H}, \mathcal{K}_{R}$ ) with the World Ocean Circulation Experiment climatology (WOCE; [54]), showing a slight under-prediction by the model in the deep ocean. Since the basin diffusivity is fixed at $\mathcal{K}_{B}$ for all experiments, unsurprisingly the model stratifications in the basin north of the SO is similar in all three experiments. This implies the secondary influence of the SO mixing on the basin stratification, consistent with theoretical arguments discussed earlier [41].

Altered SO mixing causes up to a $30 \%$ change in the strength of circulation (3d,e) after 4000 years. Increasing SO mixing to $\mathcal{K}_{H}$ and $\mathcal{K}_{R}$ increases AMOC strength by up to $\sim 3 \mathrm{~Sv}$ in the upper branch and by $\sim 2 \mathrm{~Sv}$ in the deep branch.The maximum transport is increased from $16.9 \mathrm{~Sv}$ in $\mathcal{K}_{L}$, to $17.8 \mathrm{~Sv}$ in $\mathcal{K}_{H}$, and to 18.8 in $\mathcal{K}_{R}$. Previous studies have similarly found increased strength of convection with higher SO vertical mixing [21]. The upper cell is also deepened with enhanced mixing, as in [41, 55] when mixing was increased globally, as the increased downward mixing of buoyant surface waters in the SO is able to deepen the pynocline, altering the structure of the AMOC. As we will show, this change is effective on timescales of equilibration of the circulation (centennial to millennial). We will also show that the direct impact of mixing on tracers can be more significant and effective on shorter timescales.

The distribution of $C$ and $N$ produced by the model are also qualitatively similar to observations and reproduce many of the key features (Fig.4): the surface waters are nutrient deplete due to phytoplankton productivity. As waters circulate and organic matter sinks, the $N$ and $C$ concentrations in old deep waters get enhanced (Fig 1). The short residence time of these waters in the surface SO means that biota are unable to utilize all of the nutrients [43]. Therefore, AABWs and AAIWs have high (preformed) $N$ content. The concentration of nutrients in AAIWs are rapidly depleted as waters travel north due to productivity. Regions with high (low) $N$ levels also have high (low) $C$ concentrations, as photosynthesis takes in both, and remineralisation releases both.

\section{Results: sensitivity of $C \& N$ distribution to Southern Ocean mixing}

\subsection{Multiscale temporal changes}

Figure 5 shows the $N$ distribution anomaly between various mixing scenarios and the control simulation $\left(\mathcal{K}_{L}\right)$, over the first 100 years after mixing in the SO 
is perturbed for $C \& N$ and/or density. The first row shows the total change when both $\mathcal{K}^{t}$ (which acts on $N$ and $C$ ) and $\mathcal{K}^{\rho}$ get enhanced. The net change in the first row can be interpreted as due to two contributions: (I) the indirect impact because of the change in the MOC caused by alteration of the density field by higher $\mathcal{K}^{\rho}$, and (II) the direct impact due to action of enhanced $\mathcal{K}^{t}$ directly on the $C \& N$ gradient.

The indirect impact is isolated in the second row where $\mathcal{K}^{t}$ is unchanged from the control but $\mathcal{K}^{\rho}$ is enhanced. Not surprisingly, the anomaly is large north of the SO channel, reflecting the change in the Atlantic MOC due to the modification of the Atlantic density stratification thanks to enhanced SO density mixing. The direct impact is isolated in the third row where $\mathcal{K}^{\rho}$ is unchanged from the control, but $\mathcal{K}^{t}$ is enhanced. This anomaly is expectedly SO-focused and evolves much faster than the former signal in second row.

The last row bears similarity to the first row as it too captures the impact of enhanced mixing (on both $C \& N$ and density), but for a more realistic mixing profile than the simple $\mathcal{K}_{H}=10^{-5} \mathrm{~m}^{2} / \mathrm{s}$. The SO change is more dramatic for the realistic mixing profile, since it includes the large surface turbulent mixing induced by the SO storm tracks (Fig. 2c). The higher $\mathcal{K}^{t}$ rates in the first, third, and fourth rows act to disperse the $C \& N$ more rapidly from $t C \&$ $N$-rich regions such as the AAIW and lower cell waters. $C \& N$ are lost from SO upper AAIW waters, and mixed into the $C \& N$ depleted regions above and below. Such changes are the greatest in $\mathcal{K}_{R}$, showing the importance of the enhanced surface water mixing rates.

To further quantify the changes to $\mathrm{SO}$ and basin $N$ inventories by mixing perturbations, we calculate the absolute changes between various experiments and the control run $\left(\mathcal{K}_{L}\right)$. The results are shown in Fig.6 and are broken down into different basin as well as into upper ocean versus full depth. Since the results based on $\mathcal{K}_{R}$ are similar to those experiments with $\mathcal{K}_{H}$, we don't include the former in this figure to avoid further overcrowding it.

The mean $N$ concentrations increase over the 4000 years of experiments in all regions of the Atlantic. The changes to $N$ concentrations in the surface waters of $\mathcal{K}_{H}$ show the greatest changes at all times, changing by a mean of $20 \%$ once a new steady state is reached (Fig. 6 solid red line). The SO shows initially higher changes in $N$ distributions than the basin. By 500 years, however, changes to $N$ distributions in the basin and the SO are comparable at around $13 \%$ by the time a new steady state is reached at 4000 years. This emphasizes the global impact of altered SO diapycnal mixing on $N$ distributions.

Over the first 5 years, changes to $N$ distributions are only felt in the SO and SO \& basin surface waters in experiments where $\mathcal{K}^{t}$ is enhanced. It takes over 100 years for the enhanced $\mathcal{K}^{t}$ in the SO to have an impact on the distribution of $N$ in the Atlantic basin, and even on millennial time scales, this change is less than $2 \%$. By 5 years, enhanced $\mathcal{K}^{\rho}$ alters $N$ distributions in just the SO, but only by $1 \%$, while changes to $\mathcal{K}^{t}$ alter the $N$ distributions by $4 \%$ in the same region. It takes 20 years for alterations to the MOC to alter the $N$ distributions in the basin. Changes to $N$ distributions in the basin are 
always greater for enhanced $\mathcal{K}^{\rho}$ as compared to cases with $\mathcal{K}^{T}$. In the SO, it takes at least 200 years for the indirect effect of altered MOC to alter tracer distributions more significantly than just increasing $\mathcal{K}^{t}$.

We also carried out a similar analysis for passive tracers, released with initial distributions similar to that of the $N$ distribution in the $\mathcal{K}_{L}$ experiment. The results, which are not discussed here, looked qualitatively similar to what was described above for $N$, albeit with lower magnitudes in the concentration anomalies due to the lack of biological processes.

\subsection{Long-term equilibrated changes}

While mixing is spatio-temporally variable, and so a steady-state solution does not necessarily describe the real world, it is insightful to consider the long-term equilibrated solutions of the perturbation experiments discussed above to gain an understanding of order of magnitude importance of the changes. To this end, in Fig. 7 we plot the changes in the steady-state $C$ and $N$ distributions between the various experiments and the control experiment. In all cases, the $C$ and $N$ concentrations are increased in surface waters, as found previously with enhanced SO deep water upwelling [21]. Changes to $N$ are overall more prominent than those to $C$, as shown by the percentage change contours of fig.7. The greatest changes for both occur in the $\mathcal{K}_{R}$ experiment, highlighting the conservative nature of our choice of high diffusivity in $\mathcal{K}_{H}$.

Consistent with the transient solutions, in experiments with enhanced mixing only acting on $\rho$ (panels $\mathrm{c}, \mathrm{g}$ ), the signal extends beyond the SO channel since it comes from changes to the whole AMOC. As a result, on the long-term (millennial) equilibration timescale, the indirect impact of mixing on tracers due to changes it induces in the MOC can overwhelm the effect of direct impact of mixing on tracers. However, as was discussed in relation to Figs 5, 6, on inter-annual to decadal timescales, the direct impact is dominant and perhaps more readily relevant to the short timescale climate change.

Again consistent with the transient solutions, in the experiments with enhanced mixing only applied to $N \& C$, the signal is strongest in the SO due to the transfer of tracers from the $C \& N$ rich lower cell to the upper cell of the MOC (panels b,f). The subsequent increase in the surface $N$ concentration is significant for the uptake of $C$ by biological productivity, and for the sinking of organic matter containing $C$ and $N$ as part of the biological carbon pump. An increase in surface nutrients concentrations with enhanced SO upwelling has been observed previously [21].

The climatic implications of the changes to $N$ and $C$ budgets may be encapsulated through the net change in atmospheric $\mathrm{pCO}_{2}$ concentrations between the various experiments and the control run in which weak mixing acts on $N$, $C$, and $\rho$. This is summarized in table 1 . The direct impact of enhanced mixing on tracers, as in $\left[\mathcal{K}_{H}^{t}, \mathcal{K}_{L}^{\rho}\right]$, cause the redistribution of $C$ to the upper surface waters. This is highly important for atmospheric $C$ concentrations. These surface waters allow $C$ to be exchanged between the atmosphere and the ocean. Therefore, enhanced $\mathcal{K}^{t}$ results in only a very slight increase in $C$ content of 
the upper cell, but an increase in atmospheric $C$ reservoir of 12.3ppm (Table1). Although increased $\mathcal{K}^{\rho}$ caused a stronger redistribution of $C$ to the upper cell, this $C$ was not directed to the very surface waters of the upper cell. Therefore the redistribution was not as important for ocean atmosphere fluxes of $C$, but caused more drastically observable changes to the $C$ content of the upper cell. Enhanced $\mathcal{K}^{t}$ and $\mathcal{K}^{\rho}$ both cause a steady state atmospheric $\mathrm{CO}_{2}$ concentration greater than in $\mathcal{K}_{L}$ (Table1). Increased model mixing is known to raise predicted atmospheric $\mathrm{CO}_{2}$ concentrations, and to make partitioning $\mathrm{CO}_{2}$ into the deep ocean harder [4]

\section{Discussion}

This work highlights the significant sensitivity of Atlantic nutrient and carbon distributions to enhanced vertical mixing with the Southern Ocean, demonstrating the significance of SO diapycnal mixing on biogeochemical tracer budgets. By distinguishing between the impact of SO mixing on tracers through direct tracer mixing and the indirect impact through changing the Atlantic stratification and circulation, we were able to show that both effects are significant, albeit the former acting on much shorter timescales than the latter. The direct impact due to altered tracer diapycnal fluxes manifests on inter-annual to decadal timescales. On longer timescales, the tracer concentrations are affected by the indirect impact of mixing through the change in the Atlantic MOC. The change to the Atlantic MOC by SO mixing is due to the importance of the SO density stratification to setting the Atlantic deep ocean stratification.

Changes to nutrient concentrations within the SO occur on timescales of inter-annual to decadal, while the surface water nutrient concentrations begin to be modified by the change in the MOC beyond 50 years. This timescale corresponds to transport and utilisation of nutrients by the northward SAMW [31] to be utilized for downstream productivity, as the resurfacing of deep nutrient rich waters at around $30^{\circ} \mathrm{S}$ ranges from multi-decadal to a centennial. [13]. Given that between $30^{\circ} \mathrm{S}$ and $30^{\circ} \mathrm{N}$ upper ocean nutrient supply is dominated by waters originating in the $\mathrm{SO}$, [31], the global nutrient and carbon budgets are therefore hyper-sensitive to SO mixing. Our results agree with the suggestion of [36] that flux divergences are likely to be much smaller in comparison to changes to the advective fluxes of tracers, and that increasing the diapycnal mixing values in just the $\mathrm{SO}$ causes minimal changes to vertical diapycnal nutrient fluxes, with changes to advection and convection much larger.

The steady state atmospheric $p \mathrm{CO}_{2}$ concentration was increased by $25 \mathrm{ppm}$ when a 'realistic' mixing profile (admittedly within our idealized framework) is considered relative to $\mathcal{K}_{L}$. Given that glacial inter glacial cycles in atmospheric $p \mathrm{CO}_{2}$ were around $80-100 \mathrm{ppm}$ [56], and that present day to pre-industrial atmospheric carbon changes are around 130ppm this is a highly significant result for climate modeling. This demonstrates the importance of correctly representing the strongly surface enhanced diapycnal mixing in surface waters 
of the SO for climate modelling. It also shows the importance of the choice of diapycnal mixing parameterisation in the $\mathrm{SO}$ in more advanced coupled climate models. Its significance can be further realized by noting that our analyses only included the Atlantic basin.

Fig. 8 summarizes our key messages by showing a zoomed in view of the zonally-averaged SO (from the model), and comparing the SO-branch of the upper and lower MOC between the low mixing control run and the high mixing case in which a realistic SO-averaged diffusivity was applied. The background colour, from the control run, shows the richness of nutrients in the AABW within the SO. The arrows at mid-depths represent the interior mixing induced by breaking of waves within the vigorous wave field within the SO which result in diapycnal diffusion of nutrients across density surfaces. It is the direct impact of enhancement to such mixing, which increases the rate of diapycnal upwelling of nutrients from high concentration $\mathrm{AABW}$ into the nutrient poor water masses that introduces the largest changes in Atlantic $C$ and $N$ budgets, as well as in $\mathrm{pCO}_{2}$ levels on decadal to centenial timescales. These water masses experience wind driven along isopycnal upwelling at the boundary of the upper and lower cells within the ACC (see Fig. 1). On longer timescales, alterations to nutrient distributions arise from the change in Atlantic MOC structure from enhanced SO mixing. Such mixing changes the density stratification within the SO manifesting in the form of change to density layer slopes (Fig. 8 coloured contours). Given the global connectivity of the ocean basins through the SO (thanks to the ACC system), any change in SO isopycnal slopes translates to a change to the global deep stratification, thereby to alteration of the global MOC.

Given that mixing is induced by turbulent events that are highly intermittent in time and space, this work highlights the inevitable need for realistic spatio-temporal representation of small scale $\mathrm{SO}$ mixing in climate models. In a recent complementary work, we reported a hyper-sensitivity of SO air-sea carbon fluxes to moderate changes in upper ocean diapycnal mixing in a realistic ocean state estimate[57]. While that work was focused on the SO alone, as opposed to our Atlantic focus here, it shows that our idealized framework likely significantly underestimates the sensitivity of the global budgets to the SO mixing. Even with such underprediction, the changes reported herein are significant. While some parameterization of internal wave generation within the SO have been implemented in models previously (albeit with many caveats of their own), to our knowledge, no explicit parameterization of small scale mixing within the SO has been attempted to date.

\section{References}

[1] MacKinnon, J.A., Zhao, Z., Whalen, C.B., Waterhouse, A.F., Trossman, D.S., Sun, O.M., St. Laurent, L.C., Simmons, H.L., Polzin, K., Pinkel, R., Pickering, A., Norton, N.J., Nash, J.D., Musgrave, R., Merchant, 
L.M., Melet, A.V., Mater, B., Legg, S., Large, W.G., Kunze, E., Klymak, J.M., Jochum, M., Jayne, S.R., Hallberg, R.W., Griffies, S.M., Diggs, S., Danabasoglu, G., Chassignet, E.P., Buijsman, M.C., Bryan, F.O., Briegleb, B.P., Barna, A., Arbic, B.K., Ansong, J.K., Alford, M.H.: Climate Process Team on Internal Wave-Driven Ocean Mixing. Bulletin of the American Meteorological Society 98(11), 2429-2454 (2017). https://doi.org/10.1175/BAMS-D-16-0030.1

[2] Munk, W., Wunsch, C.: Abyssal recipes II: Energetics of tidal and wind mixing. Deep-Sea Research Part I: Oceanographic Research Papers (1998). https://doi.org/10.1016/S0967-0637(98)00070-3

[3] Wunsch, C., Ferrari, R.: VERTICAL MIXING, ENERGY, AND THE GENERAL CIRCULATION OF THE OCEANS. Annual Review of Fluid Mechanics (2004). https://doi.org/10.1146/annurev.fluid.36. 050802.122121

[4] Watson, A.J., Naveira Garabato, A.C.: The role of Southern Ocean mixing and upwelling in glacial-interglacial atmospheric $\mathrm{CO} 2$ change. Tellus, Series B: Chemical and Physical Meteorology 58(1), 73-87 (2006). https://doi.org/10.1111/j.1600-0889.2005.00167.x

[5] Law, C.S., Abraham, E.R., Watson, A.J., Liddicoat, M.I.: Vertical eddy diffusion and nutrient supply to the surface mixed layer of the Antarctic Circumpolar Current. Journal of Geophysical Research C: Oceans (2003). https://doi.org/10.1029/2002jc001604

[6] Saenko, O.A., Merryfield, W.J., Lee, W.G.: The Combined Effect of Tidally and Eddy-Driven Diapycnal Mixing on the Large-Scale Ocean Circulation. https://doi.org/10.1175/JPO-D-11-0122.1

[7] Large, W.G., McWilliams, J.C., Doney, S.C.: Oceanic vertical mixing: A review and a model with a nonlocal boundary layer parameterization. Reviews of Geophysics 32(4), 363 (1994). https://doi.org/10.1029/ 94RG01872

[8] Mashayek, A., Ferrari, R., Nikurashin, M., Peltier, W.R.: Influence of Enhanced Abyssal Diapycnal Mixing on Stratification and the Ocean Overturning Circulation. Journal of Physical Oceanography (2015). https: //doi.org/10.1175/JPO-D-15-0039.1

[9] Cessi, P.: The global overturning circulation. Annual Reviews (2019). https://doi.org/10.1146/annurev-marine-010318-095241. https:// www.annualreviews.org/doi/10.1146/annurev-marine-010318-095241

[10] Talley, L.D.: Closure of the global overturning circulation through the Indian, Pacific, and southern oceans. Oceanography 26(1), 80-97 (2013). 
https://doi.org/10.5670/oceanog.2013.07

[11] Marshall, J., Radko, T.: Residual-mean solutions for the Antarctic Circumpolar Current and its associated overturning circulation. Journal of Physical Oceanography (2003). https://doi.org/10.1175/1520-0485(2003) 033<2341:RSFTAC $\rangle 2.0 . \mathrm{CO} ; 2$

[12] Ito, T., Marshall, J.: Control of lower-limb overturning circulation in the Southern Ocean by diapycnal mixing and mesoscale eddy transfer. Journal of Physical Oceanography 38(12), 2832-2845 (2008). https://doi.org/10. 1175/2008JPO3878.1

[13] Tamsitt, V., Drake, H.F., Morrison, A.K., Talley, L.D., Dufour, C.O., Gray, A.R., Griffies, S.M., Mazloff, M.R., Sarmiento, J.L., Wang, J., Weijer, W.: Spiraling pathways of global deep waters to the surface of the Southern Ocean. Nature Communications 8(1) (2017). https://doi.org/ 10.1038/s41467-017-00197-0

[14] Watson, A.J., Ledwell, J.R., Messias, M.J., King, B.A., Mackay, N., Meredith, M.P., Mills, B., Naveira Garabato, A.C.: Rapid cross-density ocean mixing at mid-depths in the Drake Passage measured by tracer release. Nature 501(7467), 408-411 (2013). https://doi.org/10.1038/ nature 12432

[15] Garabato, A.C.N., Stevens, D.P., Watson, A.J., Roether, W.: Shortcircuiting of the overturning circulation in the Antarctic Circumpolar Current. Nature 447(7141), 194-197 (2007). https://doi.org/10.1038/ nature 05832

[16] Mashayek, A., Ferrari, R., Merrifield, S., Ledwell, J.R., St Laurent, L., Garabato, A.N.: Topographic enhancement of vertical turbulent mixing in the Southern Ocean. Nature Communications 8 (2017). https://doi. org/10.1038/ncomms14197

[17] Thompson, A.F., Gille, S.T., MacKinnon, J.A., Sprintall, J.: Spatial and temporal patterns of small-scale mixing in Drake Passage. Journal of Physical Oceanography 37(3), 572-592 (2007). https://doi.org/10.1175/ JPO3021.1

[18] Ruan, X., Thompson, A.F., Flexas, M.M., Sprintall, J.: Contribution of topographically generated submesoscale turbulence to Southern Ocean overturning. Nature Geoscience (2017). https://doi.org/10.1038/ NGEO3053

[19] Marshall, J., Speer, K.: Closure of the meridional overturning circulation through Southern Ocean upwelling (2012). https://doi.org/10.1038/ ngeo1391. www.nature.com/naturegeoscience 
[20] Sloyan, B.M., Rintoul, S.R.: Circulation, renewal, and modification of antarctic mode and intermediate water. Journal of Physical Oceanography (2001). https://doi.org/10.1175/1520-0485(2001)031〈1005:CRAMOA〉2. $0 . \mathrm{CO} ; 2$

[21] Marinov, I., Gnanadesikan, A., Sarmiento, J.L., Toggweiler, J.R., Follows, M., Mignone, B.K.: Impact of oceanic circulation on biological carbon storage in the ocean and atmospheric pCO2. Global Biogeochemical Cycles (2008). https://doi.org/10.1029/2007GB002958

[22] Silvester, J.M., Lenn, Y.D., Polton, J.A., Rippeth, T.P., Maqueda, M.M.: Observations of a diapycnal shortcut to adiabatic upwelling of Antarctic Circumpolar Deep Water. Geophysical Research Letters (2014). https: //doi.org/10.1002/2014GL061538

[23] De Lavergne, C., Madec, G., Le Sommer, J., Nurser, A.J.G., Naveira Garabato, A.C.: On the consumption of Antarctic Bottom Water in the abyssal ocean. Journal of Physical Oceanography 46(2), 635-661 (2016). https://doi.org/10.1175/JPO-D-14-0201.1

[24] Naveira Garabato, A.C., Polzin, K.L., King, B.A., Heywood, K.J., Visbeck, M.: Widespread Intense Turbulent Mixing in the Southern Ocean. Science 303(5655), 210-213 (2004). https://doi.org/10.1126/ science.1090929

[25] Ledwell, J.R., St. Laurent, L.C., Girton, J.B., Toole, J.M.: Diapycnal mixing in the antarctic circumpolar current. Journal of Physical Oceanography $\mathbf{4 1}(1)$, 241-246 (2011). https://doi.org/10.1175/2010JPO4557.1

[26] Naveira Garabato, A.C., Frajka-Williams, E.E., Spingys, C.P., Legg, S., Polzin, K.L., Forryan, A., Povl Abrahamsen, E., Buckingham, C.E., Griffies, S.M., McPhail, S.D., Nicholls, K.W., Thomas, L.N., Meredith, M.P.: Rapid mixing and exchange of deep-ocean waters in an abyssal boundary current. Proceedings of the National Academy of Sciences of the United States of America (2019). https://doi.org/10.1073/pnas. 1904087116

[27] St. Laurent, L., Naveira Garabato, A.C., Ledwell, J.R., Thurnherr, A.M., Toole, J.M., Watson, A.J.: Turbulence and diapycnal mixing in drake passage. Journal of Physical Oceanography 42(12), 2143-2152 (2012). https://doi.org/10.1175/JPO-D-12-027.1

[28] Ferrari, R.: Oceanography: What goes down must come up (2014). https: //doi.org/10.1038/513179a

[29] Nikurashin, M., Ferrari, R.: Overturning circulation driven by breaking internal waves in the deep ocean. Geophysical Research Letters (2013). 
https://doi.org/10.1002/grl.50542

[30] DeVries, T., Primeau, F.: Dynamically and Observationally Constrained Estimates of Water-Mass Distributions and Ages in the Global Ocean. Journal of Physical Oceanography 41(12), 2381-2401 (2011). https://doi. org/10.1175/JPO-D-10-05011.1

[31] Palter, J.B., Sarmiento, J.L., Gnanadesikan, A., Simeon, J., Slater, R.D.: Fueling export production: Nutrient return pathways from the deep ocean and their dependence on the Meridional Overturning Circulation. Biogeosciences (2010). https://doi.org/10.5194/bg-7-3549-2010

[32] Moore, C.M., Mills, M.M., Arrigo, K.R., Berman-Frank, I., Bopp, L., Boyd, P.W., Galbraith, E.D., Geider, R.J., Guieu, C., Jaccard, S.L., Jickells, T.D., La Roche, J., Lenton, T.M., Mahowald, N.M., Marañón, E., Marinov, I., Moore, J.K., Nakatsuka, T., Oschlies, A., Saito, M.A., Thingstad, T.F., Tsuda, A., Ulloa, O.: Processes and patterns of oceanic nutrient limitation (2013). https://doi.org/10.1038/ngeo1765

[33] Sarmiento, J.L., Gruber, N., Brzezinski, M.A., Dunne, J.P.: High-latitude controls of thermocline nutrients and low latitude biological productivity. Nature 427(6969), 56-60 (2004). https://doi.org/10.1038/nature02127

[34] Klocker, A.: Opening the window to the Southern Ocean: The role of jet dynamics. Science Advances (2018). https://doi.org/10.1126/sciadv. aao4719

[35] Doney, S.C., Lindsay, K., Caldeira, K., Campin, J.M., Drange, H., Dutay, J.C., Follows, M., Gao, Y., Gnanadesikan, A., Gruber, N., Ishida, A., Joos, F., Madec, G., Maier-Reimer, E., Marshall, J.C., Matear, R.J., Monfray, P., Mouchet, A., Najjar, R., Orr, J.C., Plattner, G.K., Sarmiento, J., Schlitzer, R., Slater, R., Totterdell, I.J., Weirig, M.F., Yamanaka, Y., Yool, A.: Evaluating global ocean carbon models: The importance of realistic physics. Global Biogeochemical Cycles (2004). https://doi.org/10. 1029/2003GB002150

[36] Gnanadesikan, A., Dunne, J.P., Key, R.M., Matsumoto, K., Sarmiento, J.L., Slater, R.D., Swathi, P.S.: Oceanic ventilation and biogeochemical cycling: Understanding the physical mechanisms that produce realistic distributions of tracers and productivity. Global Biogeochemical Cycles 18(4), 1-17 (2004). https://doi.org/10.1029/2003GB002097

[37] Talley, L.D., Feely, R.A., Sloyan, B.M., Wanninkhof, R., Baringer, M.O., Bullister, J.L., Carlson, C.A., Doney, S.C., Fine, R.A., Firing, E., Gruber, N., Hansell, D.A., Ishii, M., Johnson, G.C., Katsumata, K., Key, R.M., Kramp, M., Langdon, C., Macdonald, A.M., Mathis, J.T., McDonagh, E.L., Mecking, S., Millero, F.J., Mordy, C.W., Nakano, T., Sabine, C.L., 
Smethie, W.M., Swift, J.H., Tanhua, T., Thurnherr, A.M., Warner, M.J., Zhang, J.-Z.: Changes in Ocean Heat, Carbon Content, and Ventilation: A Review of the First Decade of GO-SHIP Global Repeat Hydrography. Annual Review of Marine Science 8(1), 185-215 (2016). https://doi.org/ 10.1146/annurev-marine-052915-100829

[38] Marinov, I., Gnanadesikan, A.: Changes in ocean circulation and carbon storage are decoupled from air-sea CO\&amp;lt;sub\&amp;gt;2\&amp;lt;/sub\&amp;gt; fluxes. Biogeosciences 8(2), 505-513 (2011). https://doi.org/10.5194/bg-8-505-2011

[39] Nikurashin, M., Vallis, G.: A theory of deep stratification and overturning circulation in the ocean. Journal of Physical Oceanography 41(3), 485-502 (2011). https://doi.org/10.1175/2010JPO4529.1

[40] Wolff, G.A., Billett, D.S.M., Bett, B.J., Holtvoeth, J., FitzGeorge-Balfour, T., Fisher, E.H., Cross, I., Shannon, R., Salter, I., Boorman, B., King, N.J., Jamieson, A., Chaillan, F.: The effects of natural iron fertilisation on deep-sea ecology: The Crozet Plateau, southern Indian ocean. PLoS ONE (2011). https://doi.org/10.1371/journal.pone.0020697

[41] Nikurashin, M., Vallis, G.: A theory of the interhemispheric meridional overturning circulation and associated stratification. Journal of Physical Oceanography 42(10), 1652-1667 (2012). https://doi.org/10.1175/ JPO-D-11-0189.1

[42] Watson, A.J., Vallis, G.K., Nikurashin, M.: Southern Ocean buoyancy forcing of ocean ventilation and glacial atmospheric CO 2. Nature Geoscience (2015). https://doi.org/10.1038/NGEO2538

[43] Ito, T., Follows, M.J.: Preformed phosphate, soft tissue pump and atmospheric CO 2. Journal of Marine Research (2005). https://doi.org/10. $1357 / 0022240054663231$

[44] Mashayek, A., Ferrari, R., Vettoretti, G., Peltier, W.R.: The role of the geothermal heat flux in driving the abyssal ocean circulation. Geophysical Research Letters 40(12), 3144-3149 (2013). https://doi.org/10.1002/grl. 50640

[45] Stewart, A.L., Ferrari, R., Thompson, A.F.: On the importance of surface forcing in conceptual models of the deep ocean. Journal of Physical Oceanography 44(3), 891-899 (2014). https://doi.org/10.1175/ JPO-D-13-0206.1

[46] Ferrari, R., Jansen, M.F., Adkins, J.F., Burke, A., Stewart, A.L., Thompson, A.F.: Antarctic sea ice control on ocean circulation in present and glacial climates. Proceedings of the National Academy of Sciences of the 
United States of America 111(24), 8753-8758 (2014). https://doi.org/10. 1073/pnas.1323922111

[47] Jansen, M.F., Nadeau, L.-P.: The Effect of Southern Ocean Surface Buoyancy Loss on the Deep-Ocean Circulation and Stratification. Journal of Physical Oceanography 46(11), 3455-3470 (2016). https://doi.org/10. 1175/jpo-d-16-0084.1

[48] de Lavergne, C., Vic, C., Madec, G., Roquet, F., Waterhouse, A.F., Whalen, C.B., Cuypers, Y., Bouruet-Aubertot, P., Ferron, B., Hibiya, T., Lavergne, C., Vic, C., Madec, G., Roquet, F., Waterhouse, A.F., Whalen, C.B., Cuypers, Y., Bouruet-Aubertot, P., Ferron, B., Hibiya, T.: A Parameterization of Local and Remote Tidal Mixing. Journal of Advances in Modeling Earth Systems 12(5), 2020-002065 (2020). https: //doi.org/10.1029/2020MS002065

[49] Verdy, A., Mazloff, M.R.: A data assimilating model for estimating Southern Ocean biogeochemistry. Journal of Geophysical Research: Oceans 122(9), 6968-6988 (2017). https://doi.org/10.1002/2016JC012650

[50] Munk, W.H.: Abyssal recipes. Deep-Sea Research and Oceanographic Abstracts 13(4), 707-730 (1966). https://doi.org/10.1016/0011-7471(66) 90602-4

[51] Waterhouse, A.F., Mackinnon, J.A., Nash, J.D., Alford, M.H., Kunze, E., Simmons, H.L., Polzin, K.L., Laurent, L.C.S., Sun, O.M., Pinkel, R., Talley, L.D., Whalen, C.B., Huussen, T.N., Carter, G.S., Fer, I., Waterman, S., Naveira Garabato, A.C., Sanford, T.B., Lee, C.M.: Global patterns of diapycnal mixing from measurements of the turbulent dissipation rate. Journal of Physical Oceanography (2014). https://doi.org/10. 1175/JPO-D-13-0104.1

[52] Forget, G., Campin, J.-M., Heimbach, P., Hill, C.N., Ponte, R.M., Wunsch, C.: ECCO version 4: an integrated framework for nonlinear inverse modeling and global ocean state estimation. Geoscientific Model Development 8(10), 3071-3104 (2015). https://doi.org/10.5194/ gmd-8-3071-2015

[53] Lumpkin, R., Speer, K.: Global ocean meridional overturning. Journal of Physical Oceanography 37(10), 2550-2562 (2007). https://doi.org/10. 1175/JPO3130.1

[54] Gouretski, V., Koltermann, K.P.: WOCE global hydrographic climatology. Berichte des BSH 35, 1-52 (2004)

[55] Gnanadesikan, A.: A simple predictive model for the structure of the oceanic pycnocline. Science 283(5410), 2077-2079 (1999). https://doi. 
org/10.1126/science.283.5410.2077

[56] Sigman, D.M., Hain, M.P., Haug, G.H.: The polar ocean and glacial cycles in atmospheric CO2 concentration (2010). https://doi.org/10.1038/ nature09149

[57] Ellison, E.C., Mashayek, A., Mazloff, M.R.: Hypersensitivity of Southern Ocean air-sea carbon fluxes to turbulent diapycnal mixing (2021). https: //doi.org/10.1002/ESSOAR.10508126.1

[58] Lauderdale, J.M., Naveira Garabato, A.C., Oliver, K.I.C.C., Follows, M.J., Williams, R.G., Garabato, A.C.N., Oliver, K.I.C.C., Follows, M.J., Williams, R.G.: Wind-driven changes in Southern Ocean residual circulation, ocean carbon reservoirs and atmospheric CO 2. Climate Dynamics (2013). https://doi.org/10.1007/s00382-012-1650-3

[59] Jackett, D.R., McDougall, T.J.: A Neutral Density Variable for the World's Oceans. Journal of Physical Oceanography 27(2), 237-263 (1997). https://doi.org/10.1175/1520-0485(1997)027〈0237:ANDVFT $\rangle 2.0 . C O ; 2$

[60] Olsen, A., Lange, N., Key, R.M., Tanhua, T., Álvarez, M., Becker, S., Bittig, H.C., Carter, B.R., Cotrim da Cunha, L., Feely, R.A., van Heuven, S., Hoppema, M., Ishii, M., Jeansson, E., Jones, S.D., Jutterström, S., Karlsen, M.K., Kozyr, A., Lauvset, S.K., Lo Monaco, C., Murata, A., Pérez, F.F., Pfeil, B., Schirnick, C., Steinfeldt, R., Suzuki, T., Telszewski, M., Tilbrook, B., Velo, A., Wanninkhof, R.: GLODAPv2.2019 - an update of GLODAPv2. Earth System Science Data 11(3), 1437-1461 (2019). https://doi.org/10.5194/essd-11-1437-2019

\section{Supplementary information.}

Acknowledgments. We would like to thank Maxim Nikurashin for sharing his idealized ocean model with us.

\section{Declarations}

The authors have no conflict of interest to report. 


\begin{tabular}{|l|l|}
\hline Experiment & $\begin{array}{l}\text { change in atmospheric } \mathrm{pCO}_{2} \text { from } \mathrm{K}_{L} \\
(\mathrm{ppm})\end{array}$ \\
\hline $\mathrm{K}_{H}$ & 11.2 \\
\hline$\left[K t_{H}, K b_{L}\right]$ & 12.3 \\
\hline$\left[\mathcal{K}_{L}^{t}, \mathcal{K}_{H}^{\rho}\right]$ & 3.9 \\
\hline $\mathrm{K}_{R}$ & 24.6 \\
\hline
\end{tabular}

Table 1 Change in steady state atmospheric $\mathrm{pCO}_{2}$ from experiment $\mathcal{K}_{L}$

\section{Tables}

\section{Figures}

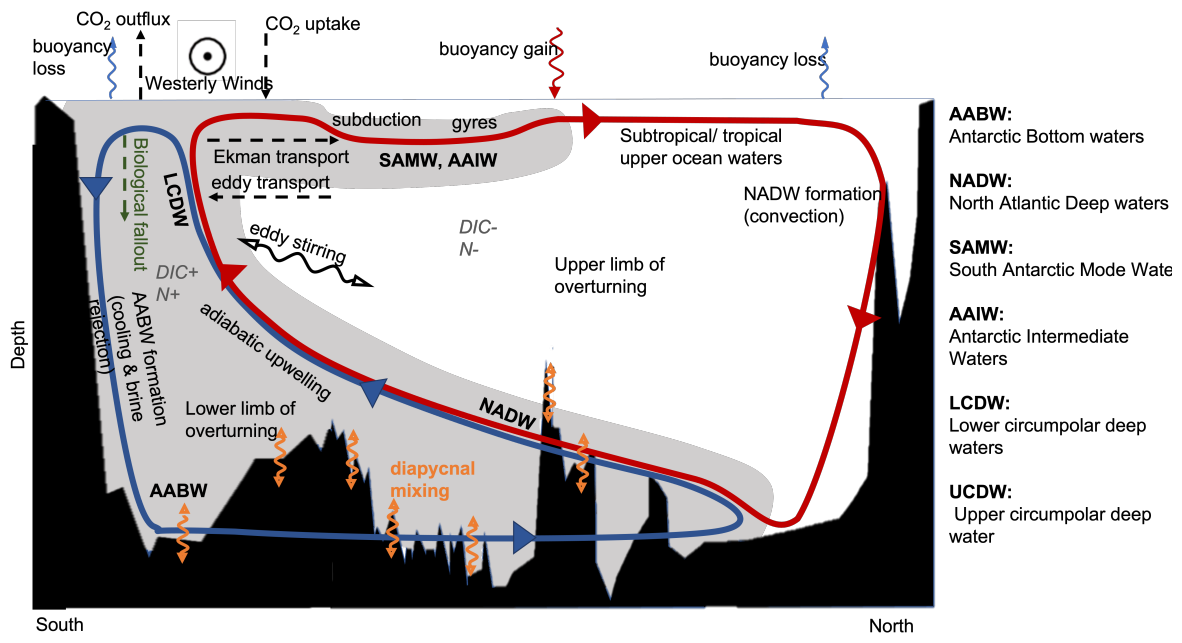

Fig. 1 A schematic of the Atlantic ocean circulation with an emphasis on the SO dynamics, watermasses, and tracers. Adapted from [58] and [10] 

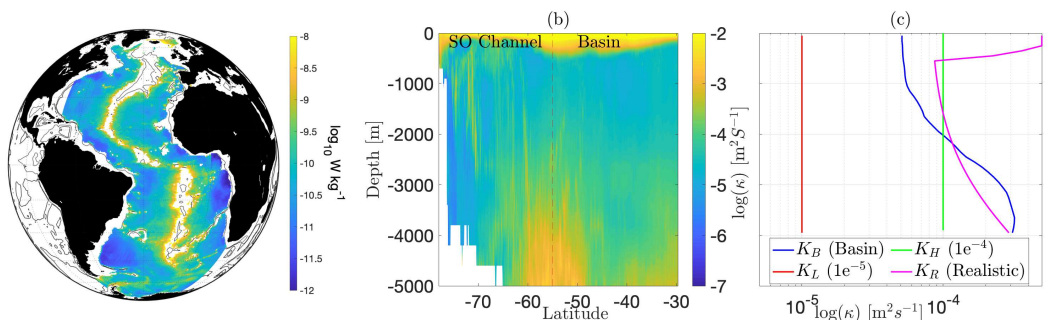

Fig. 2 a) Turbulent diffusivity in the deep Atlantic basin (3000m) based on the tidal mixing estimate of [48] and lee-wave mixing estimate of [29]. b) Zonally-averaged diapycnal mixing in the SO from a combination of the interior mixing shown in panel $a$ and wind-induced surface mixing based on the Southern Ocean Estate Estimate (SOSE; [49]). c) Basin-averaged diffusivities employed in the model: $\mathcal{K}_{B}$ is prescribed in the basin (and held the same in all experiments) whereas $\mathcal{K}_{R}, \mathcal{K}_{L}$, and $\mathcal{K}_{H}$ are employed in the $\mathrm{SO}$ for various perturbations. $\mathcal{K}_{B}$ is averaged over the basin $(32 \mathrm{~S}$ to $48 \mathrm{~N})$ based on the estimate in panel $a$. $\mathcal{K}_{R}$ is the $\mathrm{SO}$-averaged diffusivity based on the estimate in panel $b . \mathcal{K}_{L}$ and $\mathcal{K}_{H}$ are the two canonical values representing the lower and upper bounds of ocean interior mixing.
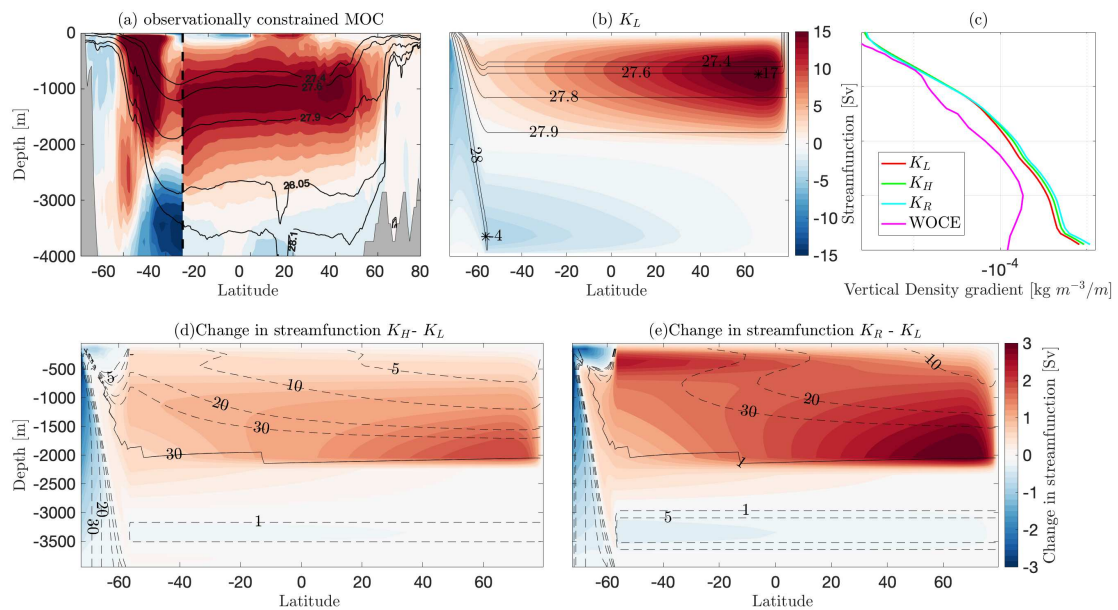

Fig. 3 a) Zonally-averaged Atlantic MOC streamfunction ( $\psi$ in Eqs. 1,2) from a climatologically-constrained ocean estimate (ECCO; $[52])$. Each $\mathrm{Sv}=10^{6} \mathrm{~m}^{3} / \mathrm{s}$. The streamfunction is calculated in the Atlantic basin up to $32^{\circ} \mathrm{S}$ and globally between $70-32^{\circ} \mathrm{S}$. b) The overturning streamfunction for the control case $\left(\mathcal{K}_{L}\right)$ with density contours overlain (black lines). c) Vertical gradient of neutral density [59] in the model basin for $\mathcal{K}_{L}$ (red), $\mathcal{K}_{H}$ (green), and $\mathcal{K}_{R}$ (blue), compared to density gradient from World Ocean circulation Experiment (WOCE [54]) climatology averaged between $48^{\circ} \mathrm{N}$ to $32^{\circ} \mathrm{S}$ in the Atlantic basin(pink). d) Change in overturning circulation between $\mathcal{K}_{H}$ and $\mathcal{K}_{L}$ experiments. Dashed lines indicate percentage change in overturning streamfunction from $\mathcal{K}_{L}$. e) Similar to $d$ but for the difference between $\mathcal{K}_{R}$ and $\mathcal{K}_{L}$. 
(a) $K_{L}$

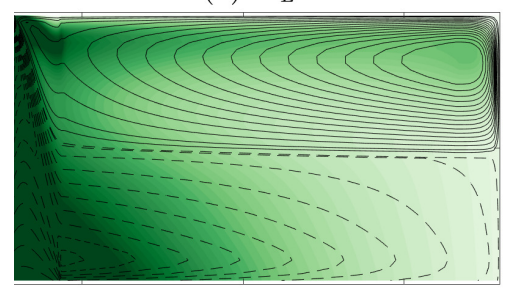

(c) $K_{L}$

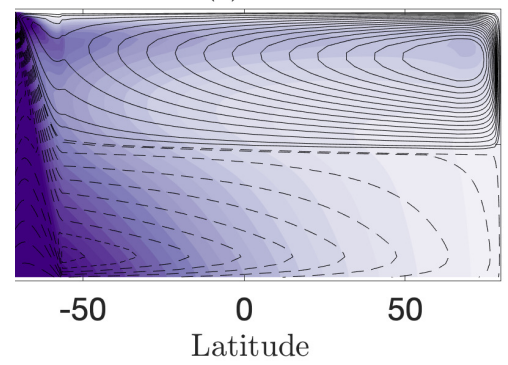

(b) WOCE mean $\left(290-20^{\circ} \mathrm{W}\right)$

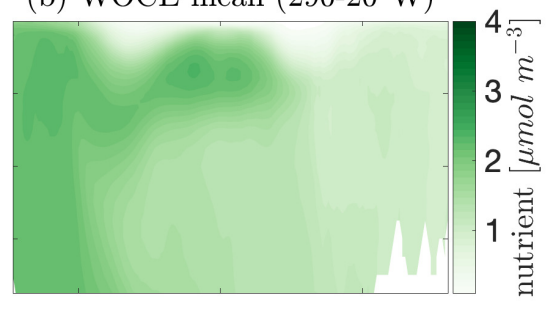

(d) GLODAP mean $\left(290-20^{\circ} \mathrm{W}\right)$

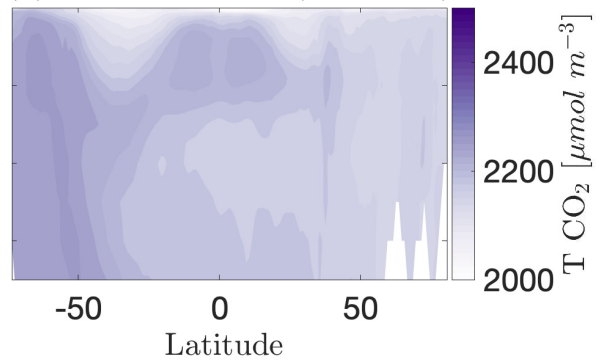

Fig. 4 Concentration of $N$ from experiment $\mathcal{K}_{L}$, compared to the climatological zonallyintegrated phosphate in the Atlantic basin from WOCE[54] in (b). Concentration of $C$ from experiment $\mathcal{K}_{L}$ in (c) is also compared to the climatological zonally-integrated $C$ from the Global Ocean Data Analysis Project (GLODAP[60]) in (d). 
(a) $K_{H^{-}} K_{L} 5$ yrs

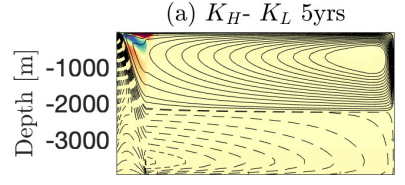

(d) $\left[\mathrm{K}_{L}^{t}, \mathrm{~K}_{H}^{\rho}\right]-K_{L} 5 \mathrm{yrs}$

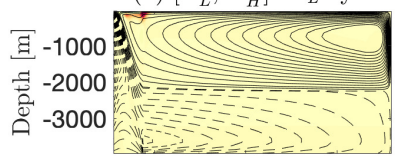

(g) $\left[\mathrm{K}_{H}^{t}, \mathrm{~K}_{L}^{\rho}\right]-K_{L} 5 \mathrm{yrs}$

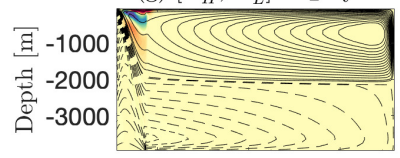

(j) $K_{R^{-}} K_{L} 5 \mathrm{yrs}$

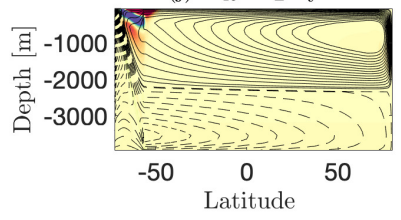

(b) $K_{H^{-}} K_{L} 50 \mathrm{yrs}$

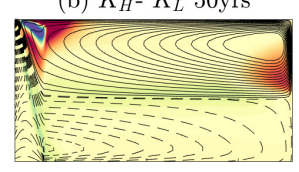

(e) $\left[\mathrm{K}_{L}^{t}, \mathrm{~K}_{H}^{\rho}\right]-K_{L} 50 \mathrm{yrs}$

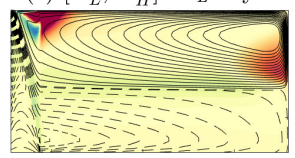

(h) $\left[\mathrm{K}_{H}^{t}, \mathrm{~K}_{L}^{\rho}\right]-K_{L} 50 \mathrm{yrs}$

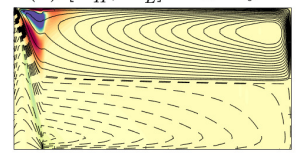

(k) $K_{R^{-}} K_{L} 50 \mathrm{yrs}$

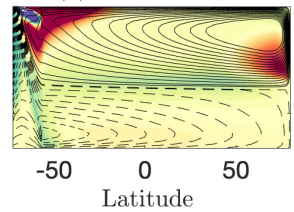

(c) $K_{H^{-}} K_{L} 100 \mathrm{yrs}$

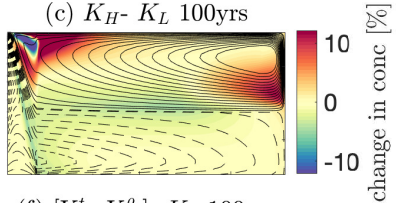

(f) $\left[\mathrm{K}_{L}^{t}, \mathrm{~K}_{H}^{\rho}\right]-K_{L} 100 \mathrm{yrs}$

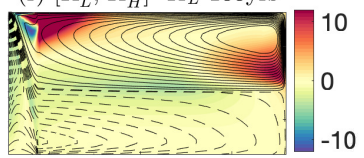

(i) $\left[\mathrm{K}_{H}^{t}, \mathrm{~K}_{L}^{\rho}\right]-K_{L} 100 \mathrm{yrs}$

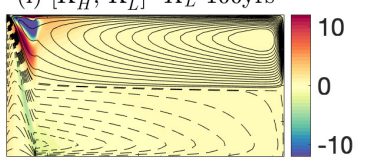

(l) $K_{R^{-}} K_{L} 100 y r s$

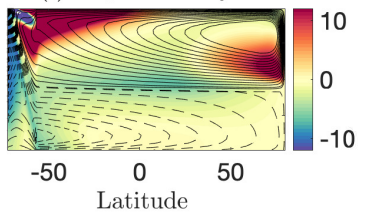

Fig. 5 Change in $N$ concentration at $\mathrm{t}=5$, 50 and 100 years. First Row: change between $\mathcal{K}_{H}$ and $\mathcal{K}_{L}$ experiments. Second Row: between $\left[\mathcal{K}_{L}^{t}, \mathcal{K}_{H}^{\rho}\right]$ and $\mathcal{K}_{L}$ experiments. Third row: between $\left[\mathcal{K}_{L}^{t}, \mathcal{K}_{H}^{\rho}\right]$ and $\mathcal{K}_{L}$ experiments. Fourth row: between $\mathcal{K}_{R}$ and $\mathcal{K}_{L}$ experiments. Red/blue implies increased/decreased tracer concentration. Black overlain lines indicate zonally averaged residual overturning circulation for each experiment. Note that the $N$ concentration for the $\mathcal{K}_{L}$ experiment is in steady-state, as was shown in figure 4a. 


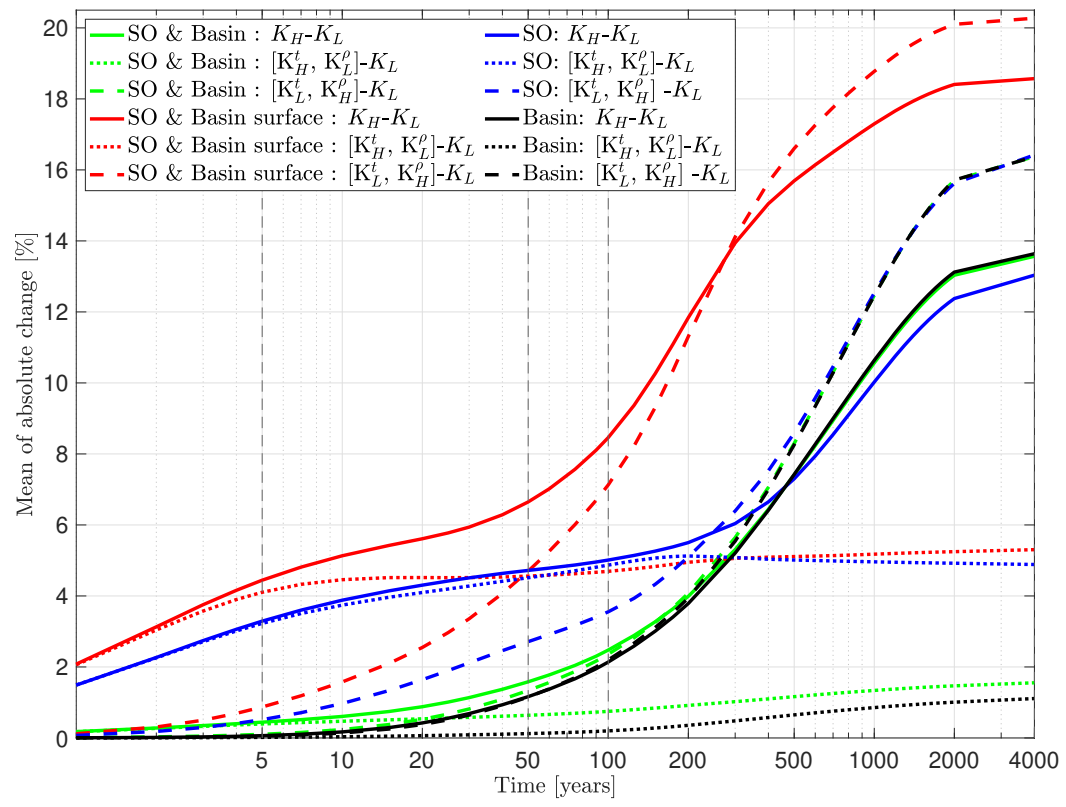

Fig. 6 Mean of absolute change in integrated $N$ concentration for various inventories: the entire ocean (SO+basin) in green, the surface ocean (top 200m of SO+basin) in red, only the basin (full depth) in black, and only the SO (full depth) in blue. Plain lines denote the difference between $\mathcal{K}_{H}$ and $\mathcal{K}_{L}$ experiments, dotted lines represent differences between $\left[\mathcal{K}_{H}^{t}, \mathcal{K}_{L}^{\rho}\right]$ and $\mathcal{K}_{L}$ experiments, and dashed lines denote differences between $\left[\mathcal{K}_{L}^{t}, \mathcal{K}_{H}^{\rho}\right]$ and $\mathcal{K}_{L}$ experiments. Vertical dashed lines indicate the time slices considered in Fig.5.

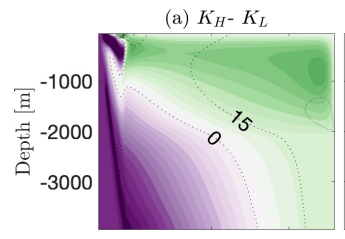

(e) $K_{H^{-}} K_{L}$

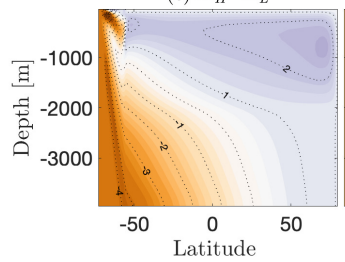

(b) $\left[\mathrm{K}_{H}^{t}, \mathrm{~K}_{L}^{\rho}\right]-K_{L}$

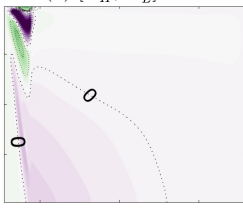

(f) $\left[\mathrm{K}_{H}^{t}, \mathrm{~K}_{L}^{\rho}\right]-K_{L}$

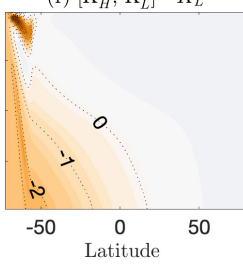

(c) $\left[\mathrm{K}_{L}^{t}, \mathrm{~K}_{H}^{\rho}\right]-K_{L}$

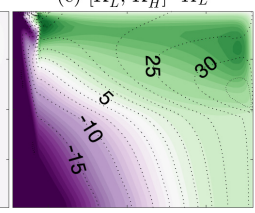

(g) $\left[\mathrm{K}_{L}^{t}, \mathrm{~K}_{H}^{\rho}\right]-K_{L}$

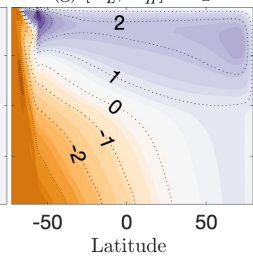

(d) $K_{R^{-}} K_{L}$

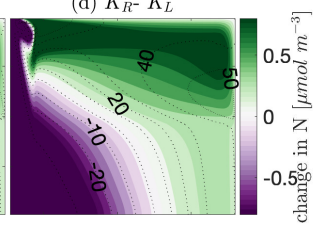

(h) $K_{R}-K_{L}$

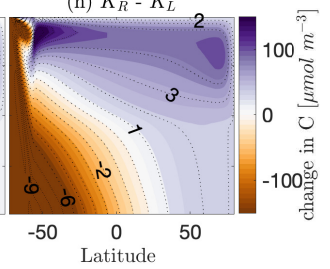

Fig. 7 Equilibrated changes to $N$ distributions. Top row: change in $N$ concentration between $\mathcal{K}_{L}$ and a) $\mathcal{K}_{H}$, b) $\mathcal{K}_{H}^{t} \mathcal{K}_{L}^{\rho}$, c) $\mathcal{K}_{L}^{t} \mathcal{K}_{H}^{\rho}$, and d) $\mathcal{K}_{R}$. Green/purple denotes regions of increased/decreased $N$ concentration. Black-labelled overlain lines indicate percentage changes from $\mathcal{K}_{L}$. Bottom row: same as above but for $C$, with purple/orange denoting regions of increased/decreased $C$ concentration. 


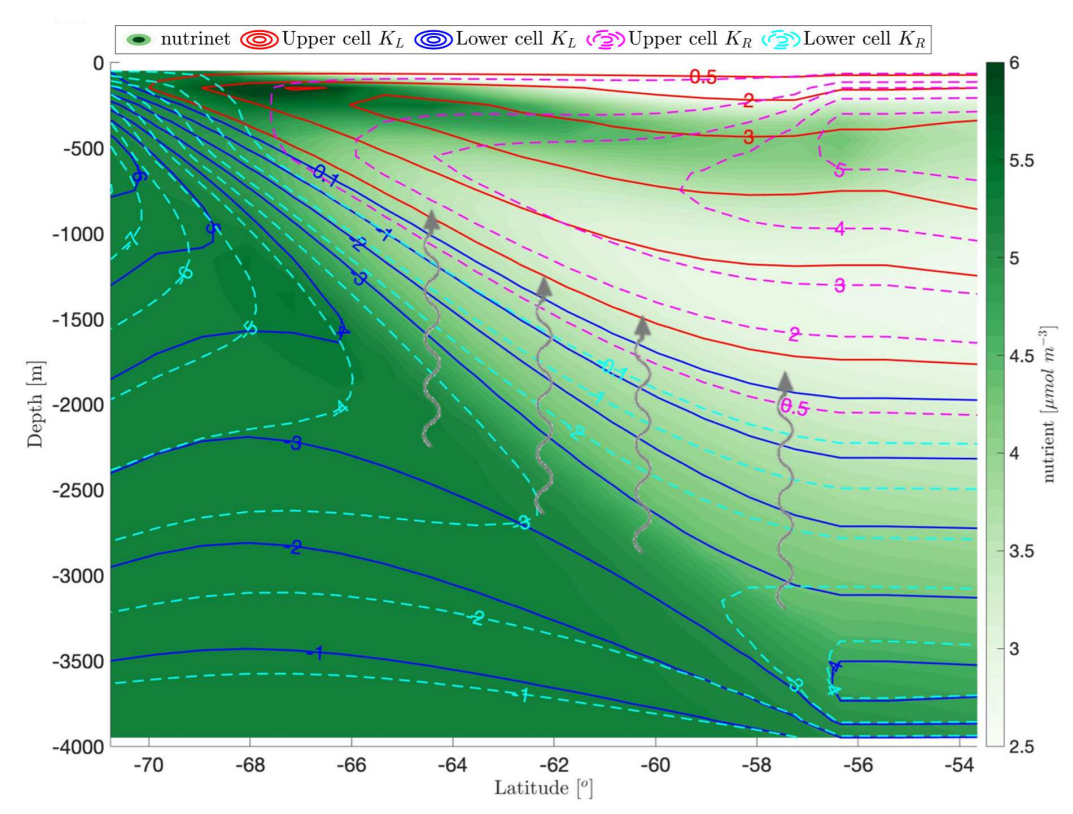

Fig. 8 Tracer distributions in the SO are altered via two processes: firstly, through the direct impact of mixing (grey arrows) on tracer gradients, and secondly by changing the SO density stratification and thereby the global MOC. Red and Blue contours show the overturning stream functions for the upper and lower MOC cells for the control $\mathcal{K}_{L}$ experiment (solid lines) vs the $\mathcal{K}_{R}$ experiment (dashed lines) in Sv. The background green colour represents the nutrient concentration from the equilibrated control experiment, $\mathcal{K}_{L}$. 